\title{
ПРЕХИРУРГИЧЕСКАЯ МР-ВИЗУАЛИЗАЦИЯ ЭПИЛЕПТОГЕННЫХ СУПРАТЕНТОРИАЛЬНЫХ ОПУХОЛЕЙ ГОЛОВНОГО МОЗГА У ДЕТЕЙ
}

\author{
${ }^{1}$ Халилов В.С., ${ }^{2,4}$ Холин А.А., ${ }^{3}$ Васильев И.Г., ${ }^{3}$ Рассказчикова И.В., ${ }^{5}$ Кисляков А.Н., \\ ${ }^{2}$ Исмаилова Р.Р., ${ }^{2}$ Заваденко Н.Н.* \\ ${ }^{\prime}$ Отделение МРТ ФГБУЗ Центральная Детская Клиническая Больница ФМБА России, Москва, РФ; \\ ${ }^{2}$ Кафедра неврологии, нейрохирургии и медицинской генетики педиатрического факультета Рос- \\ сийского Национального Исследовательского Медициского Университета им. Н.И. Пирогова \\ Минздрава РФ, г. Москва, РФ; \\ ${ }^{3}$ Отделение нейрохирургии, ФГБУ Российская Детская Клиническая больница Минздрава РФ, г. \\ Москва, РФ; \\ ${ }^{4}$ Отделение психоневрологии №2, ФГБУ Российская Детская Клиническая больница Минздрава \\ $P \Phi$, г. Москва, $Р \Phi$;
}

${ }_{5}^{5}$ Отделение патологической анатомии ФГБУ Морозовская детская городская клиническая больнииа Департамента здравоохранения г. Москвы, РФ

Симптоматические фокальные формы эпилепсии нередко обусловлены супратенториальными опухолями головного мозга. В обследованной группе из 79 пациентов детского возраста с опухолями головного мозга симптоматические формы эпилепсии наблюдались у 56 (69,3\%). Наиболее эпилептогенными опухолями явились: дизэмбриопластические нейроэпителиальные опухоли (ДНЭО), диффузные астроцитомы (ДА) и ганглиоглиомы (ГГ). Во всех отмеченных нами случаях ДНЭО и у 4-х пациентов с ГГ эпилептические приступы являлись дебютным, а в 4-х из 5-ти случаев ДНЭО - единственным клиническим проявлением опухоли. При нейровизуализации особенностями МР-картины ДНЭО, ДА и ГГ явились изо/гипоинтенсивный сигнал на Т1 взвешенном изображении (ВИ) и варьирующий по интенсивности от умеренного до гиперинтенсивного сигнала в T2 и FLAIR BИ, при этом в случаях с ДНЭО и ГГ отсутствовали масс-эффект и перифокальный отек, a во FLAIR BИ наиболее четко прослеживалась так называемая "пеноподобная" (мультикистозная) структура. За время наблюдения не отмечено существенное изменение размеров выявленных ДНЭО и ГГ. В одном случае отмечено сочетание ДНЭО с кортикальной дисплазией. При ДА трудно отличить перифокальный отек от туморозной ткани и неизмененных тканей головного мозга, а рост новообразования был замедлен. Отношение указанных опухолей к контрастному усилению неоднозначное. Наряду с ДНЭО (эпилептогенна в 100\% случаев), одними из наиболее частых эпилептогенных опухолей явились ДА (в 91.7\% случаев) и ГГ (в 80\% случаев), которые следует исключать в фармакорезистентных случаях фокальной эпилепсии.

Ключевые слова: опухоли головного мозга, симптоматическая фокальная эпилепсия, нейровизуализация.

Опухоль головного мозга - сложное и трудно поддающееся лечению заболевание. При этом имеются значительные различия в клинической картине, симптомах и течении патологического процесса у детей младшего возраста по сравнению с детьми старшего возраста и взрослыми $[1,2]$. Существует ряд опухолей, которые встречаются исключительно в детском возрасте и обладают специфическими клиническими симптомами и неоднозначной МР-картиной $[2,3]$. Большое внимание уделяется, как можно более раннему выявлению этой патологии, так как лечение пациентов детского возраста осложняется физиологической незрелостью (в том числе нервной системы), возрастными особенностями мозга и, как правило, бессимптомным течением до позд*e-mail: zavadenko@mail.ru них стадий процесса $[1,4,5]$. Критерии типичной МР-картины при опухолях широко известны и, как правило, имеют специфический характер: наличие симптома "+ткань", перифокального отека различной степени выраженности и масс-эффекта, сигнальные характеристики в режимах T2, T1 и FLAIR, а также особенности контрастного усиления, позволяют предположить наличие новообразования в тканях головного мозга [3, 6, 7]. В детском же возрасте, наиболее проблемными с точки зрения визуализации и дифференциального диагноза считаются образования, не имеющие типичных для опухоли клинической картины и МР-критериев, способные мимикрировать как под другие объёмные образования, так и различные патологические процес- 
сы в тканях головного мозга [3, 6, 8, 9]. Также затрудняет визуализацию этих внутримозговых субстратов неоднозначное отношение к контрастному усилению [3]. Считается, что незрелый мозг отличается от мозга взрослого человека предрасположенностью к ранней манифестации эпилептических приступов, которые иногда являются первым, а в некоторых случаях и единственным симптомом объемного образования $[2,4]$.

Цель исследования анализ МР - изображений, полученных при прехирургической нейровизуализации у пациентов с симптоматической эпилепсией, ассоциированной с опухолью, для определения тактики и объема хирургического вмешательства с последующей разработкой наиболее специфических МРкритериев дифференциального диагноза.

Материалы и методы. В исследование были включены 79 пациентов с опухолями головного мозга супратенториальной локализации (45 мальчиков и 34 девочки, в возрасте от 5 месяцев до 17 лет к началу наблюдения, средний возраст 9,6 \pm 5,3 года), проходившие обследование и лечение на кафедре неврологии, нейрохирургии и медицинской генетики педиатрического факультета РНИМУ и в отделениях нейрохирургии и психоневрологии №2 в РДКБ в период 2006-2014 гг. с последующим катамнезом от 1 года до 6 лет.

Магнитно-резонансная томография (МРТ) выполнялась на аппарате GE Signa infinity 1,5 Тесла, до операции, после и с последующим динамическим контролем через каждые 6 месяцев. Стандартное исследование проводилось с толщиной среза 4 или 5 мм (в зависимости от размеров головы) и шагом 2 мм, матрицей изображения 512 х 512 пикселей и включало в себя режимы визуализации Т1 и T2 взвешенное SE, FSE, FLAIR, DW и GRE T2. МРТ с высоким разрешением (МРТ ВР) проводилась с толщиной среза 1,7мм при шаге 0,1 мм, с применением специального гиппокампального позиционирования срезов. Анестезиологическое пособие для обеспечения обездвиженности пациента (методика седации севофлураном). Наркозный аппарат Aestiva-5, мониторное наблюдение проводи- лось на аппарате Datex-Ochmeda 5lS. Использовалось внутрисосудистое контрастное усиление полумолярным (гадопентенат димеглюмина) и одномолярным (гадобутрол).

Хирургические операции пациентам выполнялись в РДКБ, НИИ нейрохирургии им. Н.Н.Бурденко и клинике Behandlungszentrum Vogtareuth (Фогтаройт, Бавария). Гистологические образцы были фиксированы в забуференном формалине, залиты в парафиновые блоки, из которых были изготовлены срезы толщиной 3 микрометра. Во всех случаях проводили рутинную окраску гематоксилином и эозином, а также иммуногистохимическое исследование с антителами к глиальному фибриллярному кислому белку, синаптофизину, белку нейрофиламентов, виментину, CD34, маркеру пролиферативной активности Ki-67, общему цитокератину. Формулировку диагнозов проводили в соответствии с действующей классификацией опухолей ЦНС BO3. (IARC, Lyon, 2007).

Результаты исследования. У 77 из 79 обследованных пациентов $(97,3 \%)$ наличие опухоли было подтверждено исследованиями МРТ и КТ. МРТ ВР применялась в 13 случаях, когда рутинная МРТ не выявила структурных изменений регионов головного мозга, кореллирующих с фокальными изменениями на ЭЭГ, или изменения были минимальных размеров. В одном случае с помощью МРТ ВР удалось выявить, а потом и гистологически подтвердить, сочетание фокальной кортикальной дисплазии (ФКД II) с ДНЭО (Рис. 4). МР - характеристики большинства опухолей заключались в наличии зон патологического сигнала имеющего гипо-, или гиперинтенсивные характеристики на T1, T2 и FLAIR ВИ, с или без четкого ограничения от мозговой ткани, наличием перифокального отека и масс-эффекта в 52 случаях. Накопление контрастного препарата зарегистрировано в 49 случаях, у 9 пациентов было отмечено интенсивное накопление контрастного агента опухолевым субстратом (узловой тип), в 7 случаях отмечалось глубокое кольцевидное накопление, в 3-х по типу некротического кольцевидного, в 6 точечное (мелкоочаговое) накопление, в остальных 24 случаях кистозноузловое. Также надо заметить, что в 9 случаях 
использования одномолярного препарата (гадобутрола) отмечалось контрастное усиление различной степени интенсивности образований, которые ранее были контраст-негативными. В 23 случаях из 27 субтотальных резекций опухолевого субстрата, постоперационная
МРТ выявила признаки остаточной опухоли, в 7 случаях отсроченные динамические МРТ выявили продолженный рост. Гистологические варианты опухолей полученных при исследовании были объединены в группы согласно классификации ВОЗ 2007 г. (таб. 1)

Таблица 1.

\section{Гистологические характеристики опухолей и их эпилептогенность в наблюдаемой группе}

\begin{tabular}{|c|c|c|c|}
\hline Опухоли ЦНС & С эпилепсией & Без эпилепсии & Достоверность (p) \\
\hline Глиальные опухоли & 26 & 7 & $\mathrm{P}<0,05$ \\
\hline Эпендимарные & 4 & 2 & $\mathrm{P}>0,5$ \\
\hline Нейронально-глиальные & 20 & 4 & $\mathrm{P}<0,05$ \\
\hline Сосудистого сплетения & 2 & 5 & $\mathrm{P}<0,5$ \\
\hline Эмбриональные & 1 & - & $\mathrm{P}>0,5$ \\
\hline Менинготелиальные & 3 & - & $\mathrm{P}>0,5$ \\
\hline Селлярной области & - & 4 & $\mathrm{P}<0,01$ \\
\hline Пинеальной области & - & 1 & $\mathrm{P}<0,5$ \\
\hline Всего & 56 & 23 & \\
\hline
\end{tabular}

Согласно полученным данным, в количественном и процентном соотношении наиболее эпилептогенными опухолями в исследуемой группе (n=79) явились: ДНЭО, которые в 100\% случаев сопровождались симптоматической эпилепсией, ДА - в 91,7\% случаев бывшие эпилептогенными, и ГГ - в 80\% случаев с наличием эпилепсии. При визуализации этих опухолей довольно часто возникали трудности в трактовке полученных МР - изображений, по требовавшие проведения дифференциального ряда, продолжительного дополнительного динамического наблюдения и в конечном итоге биопсии. Наиболее часто дифференциальный диагноз проводился между опухолевым процессом и последствиями перенесенных регионарных ОНМК или нейроинфекции. Основные МР - особенности гистопатологически подтвержденных ДНЭО, ДА и ГГ, их локализация и отношение к контрастному усилению, представлены в таблице 2 .

Таблица 2.

\section{Основные МР - характеристики эпилептогенных новообразований головного мозга по данным нейровизуализиации в исследуемой группе}

\begin{tabular}{|c|c|c|c|c|c|c|c|}
\hline $\begin{array}{c}\text { Вид } \\
\text { опухоли }\end{array}$ & $\begin{array}{l}\text { Число } \\
\text { случаев }\end{array}$ & $\begin{array}{l}\text { Эпи- } \\
\text { лепсия }\end{array}$ & Локализация опухоли & $\begin{array}{c}\text { Сигнальные } \\
\text { характеристики }\end{array}$ & $\begin{array}{l}\text { Структура } \\
\text { опухоли }\end{array}$ & $\begin{array}{c}\text { Контрастное } \\
\text { усиление (тип) }\end{array}$ & $\begin{array}{c}\text { Масс-эффект / } \\
\text { Перифокальный отек }\end{array}$ \\
\hline ДНЭо & 8 & 8 & $\begin{array}{l}\text { Правая височная доля - } 4 \\
\text { Левая височная доля - } 2 \\
\text { Правый теменно-затылочный } \\
\text { регион - } 1 \\
\text { Правая затылочная доля - } 1\end{array}$ & $\begin{array}{l}\text { Гипоинтенсивные в } \\
\text { T1 ВИ, } \\
\text { гиперинтенсивные/ } \\
\text { умеренно } \\
\text { неоднородные в T2 } \\
\text { и FLAIR BИ } \\
\end{array}$ & $\begin{array}{l}\text { Мелкокистозная - } \\
2 ; \\
\text { Кистозно- } \\
\text { солидная - } 4 \\
\text { Узловая - } 2 ;\end{array}$ & $\begin{array}{l}4 \text { случая: } \\
\text { Мелкоочаговый- } \\
\text { точечный - } 2 \\
\text { Кистозно- } \\
\text { солидный - } 2\end{array}$ & $\begin{array}{l}\text { Незначительный в } 1 \\
\text { случае. } \\
\text { Перифокальный отек- } \\
\text { нет. }\end{array}$ \\
\hline ДА & 12 & 11 & $\begin{array}{l}\text { Теменная доля }-4 \\
\text { Лобная доля }-3 \\
\text { Височная }-2 \\
\text { Теменно-затылочный регион - } \\
2 \\
\text { Задневисочно-теменной } \\
\text { регион - } 1\end{array}$ & $\begin{array}{l}\text { Гипо/ } \\
\text { изоинтенсивные в } \\
\text { Т1ВИ, } \\
\text { гиперинтенсивные/ } \\
\text { неоднородные в T2 } \\
\text { и FLAIR ВИ }\end{array}$ & $\begin{array}{l}\text { Кистозно- } \\
\text { солидная - } 3 \\
\text { Мелкокистозная - } \\
1 \\
\text { Узловая - } 8\end{array}$ & $\begin{array}{l}7 \text { случаев: } \\
\text { Кистозно- } \\
\text { солидный тип }-3 \\
\text { Узловой - } 1 \\
\text { мелкоочаговый- } \\
\text { точечный }-3\end{array}$ & $\begin{array}{l}\text { Масс-эффект разной } \\
\text { степени выраженности } \\
-8 \text { случаев. } \\
\text { Перифокальный отек } \\
\text { разной степени } \\
\text { выраженности - } 11 \\
\text { случаев }\end{array}$ \\
\hline$\Gamma \Gamma$ & 11 & 9 & $\begin{array}{l}\text { Теменная доля }-3 \\
\text { Лобная доля }-2 \\
\text { Височная доля }-3 \\
\text { Теменно-височный регион }-2 \\
\text { Правая затылочная доля }-1\end{array}$ & $\begin{array}{l}\text { Гипоинтенсивные в } \\
\text { Т1ВИ, } \\
\text { гиперинтенсивные/ } \\
\text { умеренно } \\
\text { неоднородные в T2 } \\
\text { и FLAIR BИ } \\
\end{array}$ & $\begin{array}{l}\text { Кистозно- } \\
\text { солидная- } 4 \\
\text { Мелкокистозная - } \\
1 \\
\text { Узловая - } 6\end{array}$ & $\begin{array}{l}3 \text { случая: } \\
\text { Узловой - } 1 \\
\text { Мелкоочаговый- } \\
\text { точечный - } 2 \\
\text { Кистозно- } \\
\text { солидная - } 1 \\
\end{array}$ & $\begin{array}{l}\text { Масс-эффект } \\
\text { отсутствует. } \\
\text { Перифокальный отек - } \\
1 \text { случай. }\end{array}$ \\
\hline
\end{tabular}


Приводим случаи, потребовавшие долгого динамического наблюдения и сочетания различных методов диагностики для постановки дифференциального диагноза между опухолевым процессом и другими патологическими состояниями головного мозга.

Клинический случай. Пациентка С. 8 лет, поступила с диагнозом "последствия перенесенной нейроинфекции неясной этиологии. Симптоматическая височная эпилепсия" (Рис. 1). В 2,5 года появилось расходящееся косоглазие и стереотипные движения в виде раскачивания туловища и сосания большого пальца. В 3 года отмечен парциальный приступ с вторичной генерализацией (в виде поворота головы влево с последующей утратой сознания около 20 секунд). Повторный приступ через 2 недели. На МРТ, проведенной по месту жительства, было заподозрено объемное образование в правой гемисфере. После консилиума, учитывая отсутствие динамических изменений субстрата и контрастного усиления, заподозрен лейкоэнцефалит. Проведена люмбальная пункция - белок 0,048 г/л, цитоз 2/3. Не найдены ДНК герпеса и ЦМВ в ликворе. Повышен титр антител к кори 1:160., На фоне гормональной терапии положительного эффекта не наблюдалось. В 3 года 9 мес. появилось нарушение походки, речи, снижение памяти и учащение приступов. В 4 года появились атоническиастатические приступы и генерализованные вздрагивания во сне до 10 эпизодов в сутки. МРТ в динамике от 2004 г., 2007 г., 2009 г. - без существенных изменений. Неоднократно находилась на обследовании и лечении в ПНО № 2, дифференциальный диагноз проводился между хроническим течением лейкоэнщефалита, псевдотуморозной формы (лейкоэнцефалит Шильдера), последствиями перенесенного вирусного (герпетического) энцефалита и опухолевым процессом. В последний раз находилась на лечении в ПНО № 2 с 22.06.2009 по 11.07.2009 г. Для уточнения диагноза, было решено провести парциальную резекцию височной доли правого полушария головного мозга (1/2), биопсию, с использованием микронейрохирургической техники и операционного микроскопа (Рис. 2).
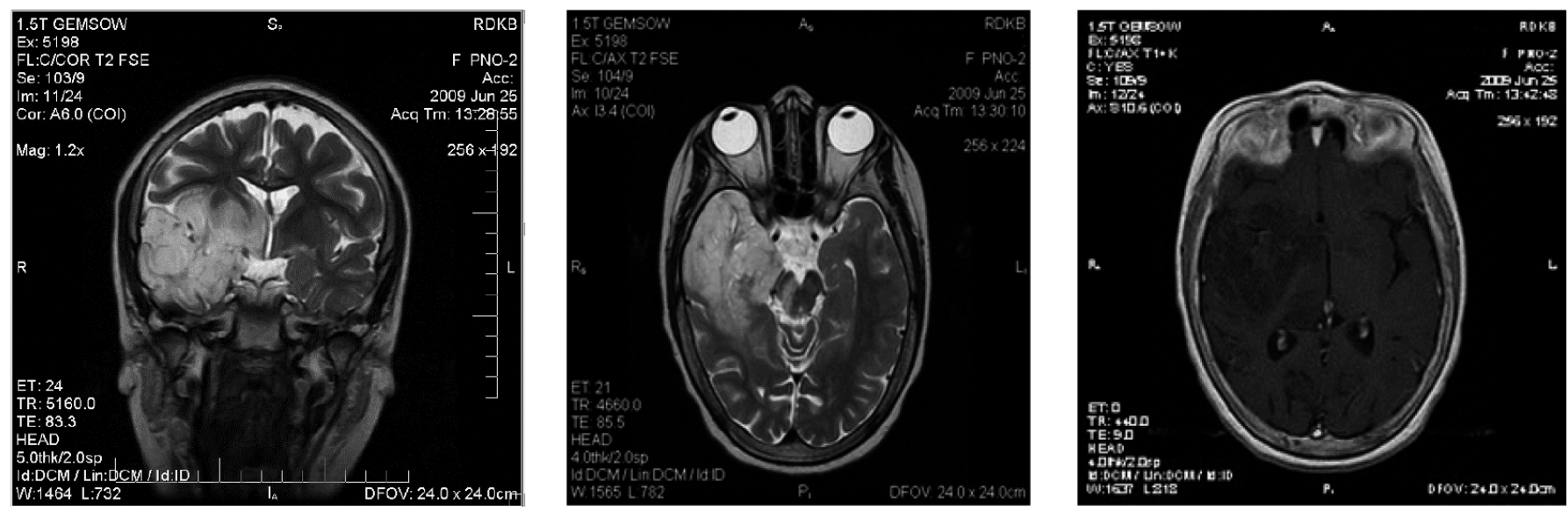

Рис.1. Больная С. 8 лет. ДНЭО. В Т2 ВИ (а, б) отмечается обширная зона патологического сигнала охватывающая правую височную долю, вовлекающая подкорковые узлы, таламус, ножку мозга и мост справа. Также отмечаются перивентрикулярные очаги повышенной интенсивности в Т2 ВИ в белом веществе вокруг задних рогов боковых желудочков в теменно-затылочных областях, легкое смещение срединных структур на 2-3 мм влево. В Т1 ВИ с в/в введением МРКС (в), - контрастного усиления вышеописанными изменениями не наблюдается. Диагноз при поступлении: последствия перенесенной нейроинфекции неясной этиологии.

Гистологический диагноз ДНЭО был перепроверен в НИИ НХ им Н.Н. Бурденко и в ФГБУ ФНКЦ им. Д.Рогачева. В постоперационном периоде развился эпилептический статус фокальных моторных приступов. Купирован введением конвулекса 1000 мг в/в болюсно. На ЭЭГ отмечалась продолженная электро-клиническая иктальная активность статусного характера. В последующем в терапию введен топамакс 25 мг в сутки. Неврологический статус в постоперационном периоде: расходящееся косоглазие с 2-х сторон. Недоведение глазных яблок кнутри. Слабость конвергенции, больше справа. Сглаженность левой носогубной складки. Девиация языка вправо. Иногда поперхивается при еде. Глоточные и небные рефлексы снижены. Дизартрия. Левосторонний гемипарез. Сухожильные рефлексы вызываются, больше слева. Мышечная сила снижена в левых конечностях. С-м Бабинского с 2х сторон. 

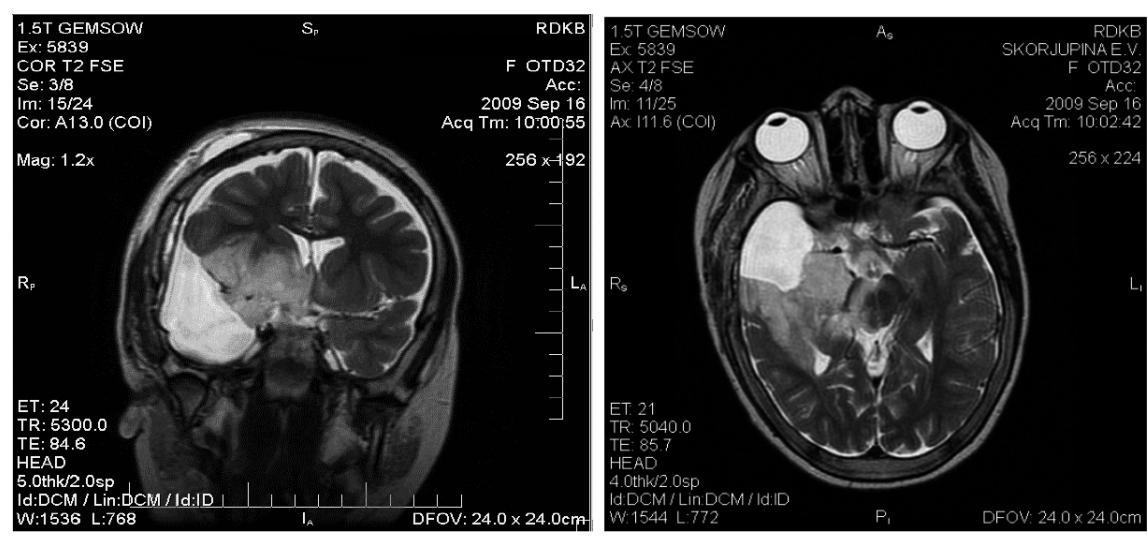

Рис. 2. Больная С. 8 лет. ДНЭО. На серии МР-томограмм определяется постоперационная киста в области правого гиппокампа и наличие остаточной опухоли в правой височной доле с вовлечением в процесс подкорковых структур.

Позднее на фоне терапии антиэпилептическими препаратами (АЭП) отмечалось выраженное уменьшение частоты и длительности приступов. Постоперационный катамнез составил 5 лет. Продолжали отмечаться приступы (атоническиастатические и генерализованные вздрагивания во сне до 5 эпизодов в сутки) - исход Engel class III.

ДНЭО были диагностированы у 8 пациентов, 4 мальчика и 4 девочки. За время катамнеза было проведено не менее 3 динамических МРТ исследований до хирургического вмешательства, которые не выявили существенных изменений размеров и конфигурации опухолей. Ниже продемонстрированы наиболее трудные случаи дифференциального диагноза ДНЭО и других патологических изменений вещества мозга (Рис. 3, 4). В трех случаях было зафиксировано расхождение диагноза, в первом случае дифференцирование проводилось между хроническим течением лейкоэнцефалита (псевдотуморозной формой) и опухолевым процессом (Рис. 1-2). Во втором случае (Рис.3) дифференциальный диагноз проводился между последствиями ОНМК, очагом регионарной дисциркуляции и опухолью. В третьем (Рис. 4), образование было минимальных размеров, входило в структуру зон перивентрикулярной лейкопатии. Долгое время диагноз трактовался как последствия гипоксическиишемического поражения. Только после проведения МРТ ВР было отмечено сочетание нарушения серо-белой дифференциации и очаговых изменений, позволившее предположить наличие "двойной" патологии. Во всех случаях была отмечена задержка психомоторного развития, а дебютным и ведущим симптомом опухоли были фармакорезистентные, прогредиентные эпилептические приступы.
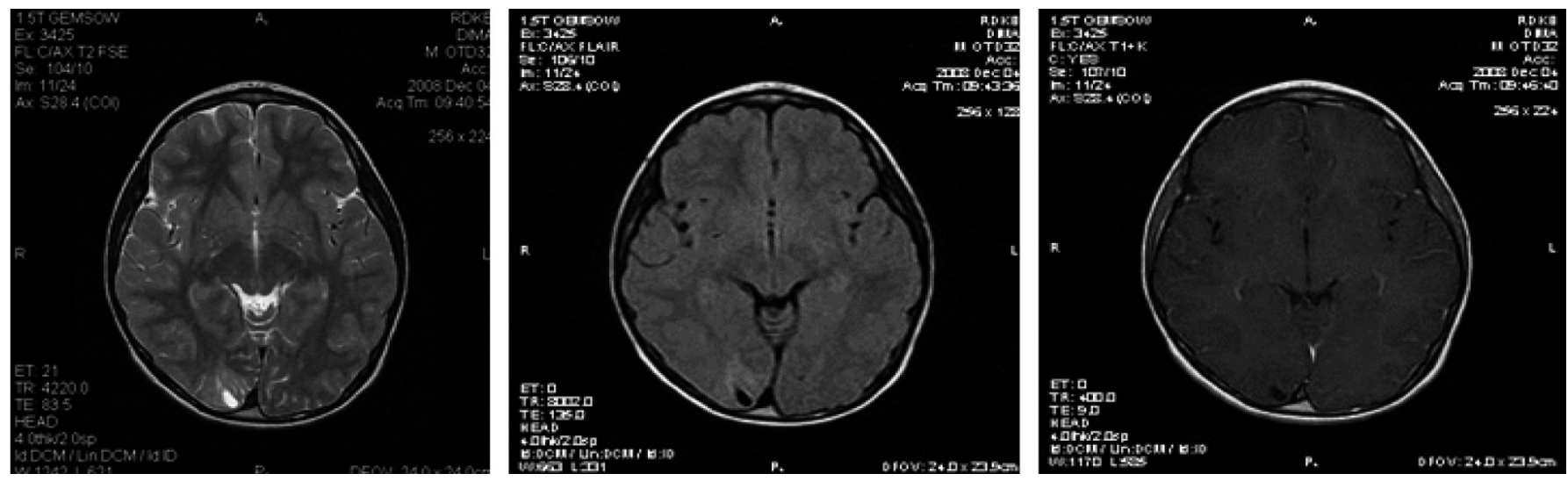

Рис.3. Больной М 7 лет. ДНЭО субкортикальных отделов правой затылочной доли. Симптоматическая эпилепсия. На представленных MP - изображениях в T2 (a), FLAIR ВИ (б), определяется небольших размеров опухоль, имеющая кистозный компонент и умеренно гиперинтенсивный сигнал в T2 и FLAIR BИ от перикистозной ткани, в субкортикальных отделах правой затылочной доли с вовлечением кортикальной пластинки. Масс-эффект отсутствует, перифокального отека нет. Контрастное усиление в режиме Т1 ВИ (в) не выявило патологического накопления. Диагноз при поступлении: кистозно-глиозная трансформация в правой затылочной доле, последствия регионарной дисциркуляции в бассейне правой ВБА? 


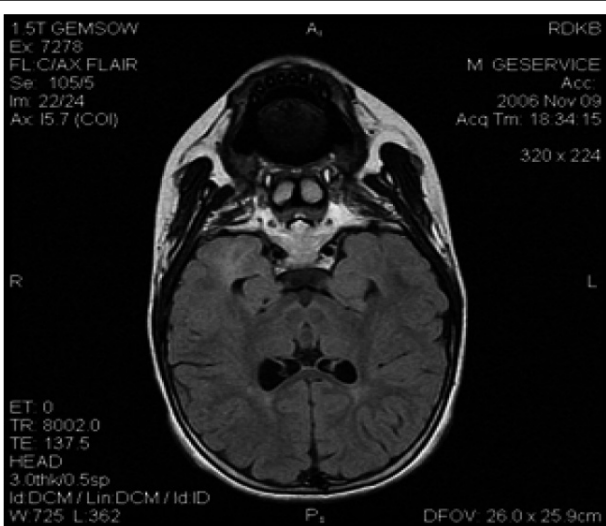

a)

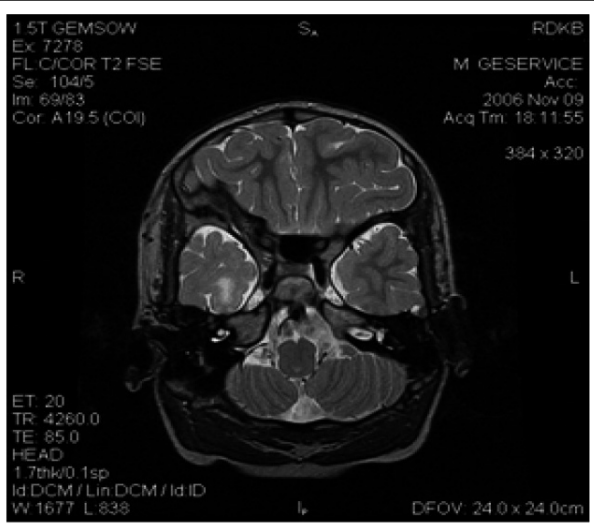

б)

Рис. 4. Больная Д. 6 лет. "Двойная" патология ДНЭО в сочетании с ФКД II типа полюса правой височной доли. Симптоматическая эпилепсия. МРТ ВР (специальное гиппокапмпальное позиционирование срезов). На представленных изображениях во FLAIR ВИ (а) - зона слабогиперинтенсивного сигнала в субкортикальных с распространением на кортикальные отделы переднего полюса правой височной доли. При МРТ ВР (б) визуализируется очаговое изменение сигнала в Т2 ВИ, нарушение серо-белой дифференциации полюса височной доли и его локальная атрофия. Перифокального отека нет, контрастное усиление стромы опухоли отсутствует. Диагноз при поступлении: Последствия резидуального гипоксически-ишемического поражения (перивентрикулярная лейкомаляция) головного мозга.

Диффузные астроцитомы (ДА) были диагностированы у 12 пациентов: 6 мальчиков и 6 девочек. В 9 случаях диагноз объемное образование, был поставлен по данным МРТ. В трех случаях, структуру опухоли было достаточно сложно отдифференцировать от минимально выраженного перифокального отека и неизмененной мозговой ткани (Рис. 5 a, б). При динамическом наблюдении, в 6 случаях был отмечено увеличение размеров. Три опухоли, описанные на момент наблюдения как контрастнегативные, начали в различной степени копить контрастный препарат за время наблюдения.
Наиболее интересный случай представлен ниже.

Клинический случай. Больной М. 12 лет. Ребенок наблюдался в ДКБ по месту жительства с диагнозом: симптоматическая височная эпилепсия. Фармакоризистентная форма. Приступы в виде тонического напряжения конечностей, приведения правой верхней конечности к туловищу, адверсии головы и глаз вправо, клонических сокращений правой половины лица. Длительность приступа 1-3 минуты. В неврологическом статусе, на фоне общей нормы, перманентно отмечались общемозговые симптомы (как правило, в межприступный период) и слабость в левой руке.

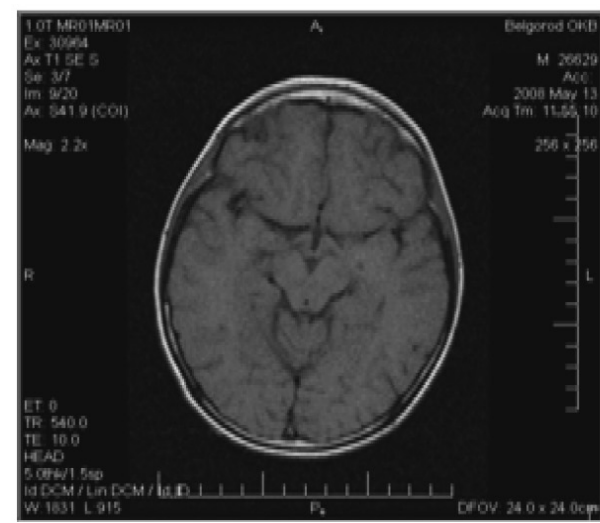

a)

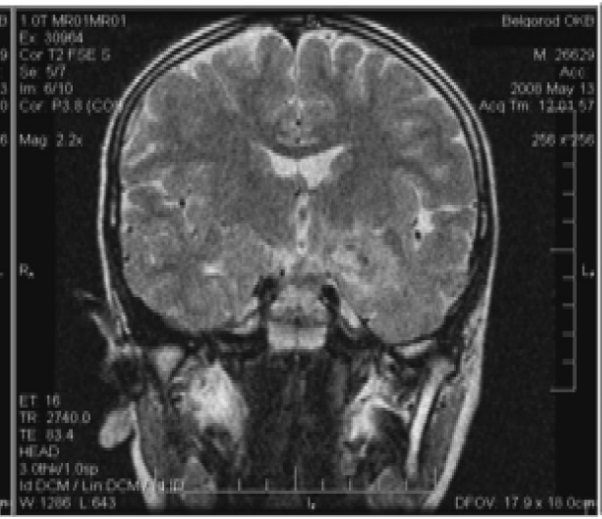

б)

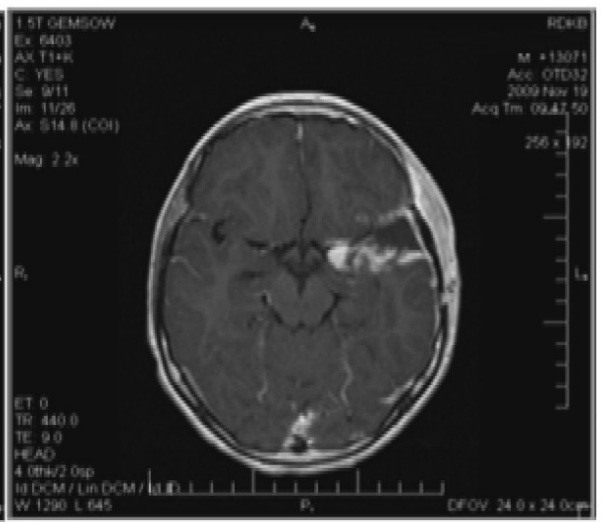

B)

Рис. 5. Больной М. 12 лет. Диффузная астроцитома медиальных отделов левой височной доли. Визуализируется слабо различимая зона повышенного сигнала в Т2 ВИ (б) с нечеткими, неровными контурами, без четкого отграничения от ткани мозга. В режиме Т1 ВИ (а) выявленные изменения интактны. Отсутствуют перифокальный отек, минимально выражен масс-эффект (компримирован височный рог гомолатерального желудочка), при контрастном усилении патологического накопления контрастного агента не выявлено, на постоперационных изображениях (в) отмечается реактивное накопление МРКС по границам постоперационных изменений. Диагноз при поступлении: левосторонний мезиальный темпоральный склероз. 
Регулярно по месту жительства проводились МРТ головного мозга с контрастным усилением, заключение: патологических изменений вещества головного мозга не выявлено. Позже, после консультации снимков в НИИ НХ им. Бурденко, было отмечено изменение сигнала в T2 и FLAIR ВИ в медиобазальных отделах левой височной доли. На МРТ ВР выполненной для подтверждения данного предположения, дифференциальный диагноз проводился между опухолевым процессом (ДНЭО, ГГ) и мезиальным темпоральным склерозом. В возрасте 3 лет отмечено появление больших генерализованных приступов с потерей сознания. В 2005 году проведена МРТ головного мозга - выявлено незначительное увеличение размеров патологической зоны. Проведено хирургическое вмешательство субтотальное удаление опухоли, частичная резекция височной доли с использованием интраоперационной кортикографии. Гистологический диагноз: пилоидная астроцитома Gr 1. В постоперационном неврологическом статусе отмечается нарушение пронации в левой кисти. Выписан в удовлетворительном состоянии, рекомендовано, продолжать противосудорожную терапию. На настоящее время послеоперационный катамнез составляет 5 лет. Отмена АЭП 2 года назад. Приступов не отмечается - исход Engel class I.

Кроме того, в ходе работы были диагностированы 11 ганглиоглиом (ГГ), у 8-ми мальчиков и трех девочек. Как и в случаях с ДНЭО они отличались стертой клинической картиной, в которой превалировали фармакорезистентные эпилептические приступы и задержка психо-речевого развития. Также в 5 случаях потребовалось проведение дифференциального диагноза между опухолевым процессом и кистозно-глиозной трансформацией вещества мозга как последствия перенесенного острого нарушения мозгового кровообращения (ОНМК). В двух случаях, когда опухоль располагалась в конвекситальных отделах полюсов височных долей, она долгое время расценивалась как врожденные арахноидальные кисты.
Клинический случай. Больная К.М., 14 лет с диагнозом ганглиоастроцитома теменно-затылочной области справа. Симптоматическая эпилепсия. Поступила с жалобами: на периодические эпилептические приступы, сопровождающиеся кратковременной потерей сознания. В 2006 г. впервые отмечены 2 эпизода кратковременной потери сознания. Через три месяца - генерализованные тонические приступы, госпитализирована в неврологическое отделение областной ДКБ. Отмечались приступы: изолированные потери сознания с оседанием ("синкопоподобные" приступы); редкие вторично-генерализованные тонические приступы; эпилептическое вертиго приступы головокружений - частотой от 1 раз в неделю до 2 раз в сутки. По данным МРТ объёмное образование теменно-затылочного региона справа. Назначены АЭП - без существенного эффекта. Через месяц проведена повторная МРТ с контрастным усилением, не выявившая изменений. Было рекомендовано дообследование - МРА (ангиография) для исключения АВМ. МРА не выявила наличия мальформации. При дооперационном динамическом МР - контроле в 2006, 2007 гг., изменений не выявлено, контрастного усиления не отмечалось. Дифференциальный диагноз проводился с зоной кистозно-глиозной трансформации после перенесенного ОНМК. В неврологическом статусе: В сознании, контактна. Общемозговой и менингеальной симптоматики нет. Лицо симметрично. Подвижность глазных яблок полная. Зрачки равные. Корнеальные рефлексы не снижены. Глоточный рефлекс снижен. Мышечный тонус и сила достаточны и равномерны. Сухожильные рефлексы без разницы сторон, симметричны. Координаторные пробы выполняет уверенно. 10.04.2007 было проведено хирургическое вмешательство: Фокальная резекция изменённой коры теменно-затылочной локализации справа, биопсия (Рис. 7). Зона резекции опухолевого субстрата и эпилептогенной перитуморальной ткани корректировалась по ходу резекции с помощью электрокортикографии. Гистологический диагноз - ганглиоастроцитома. 

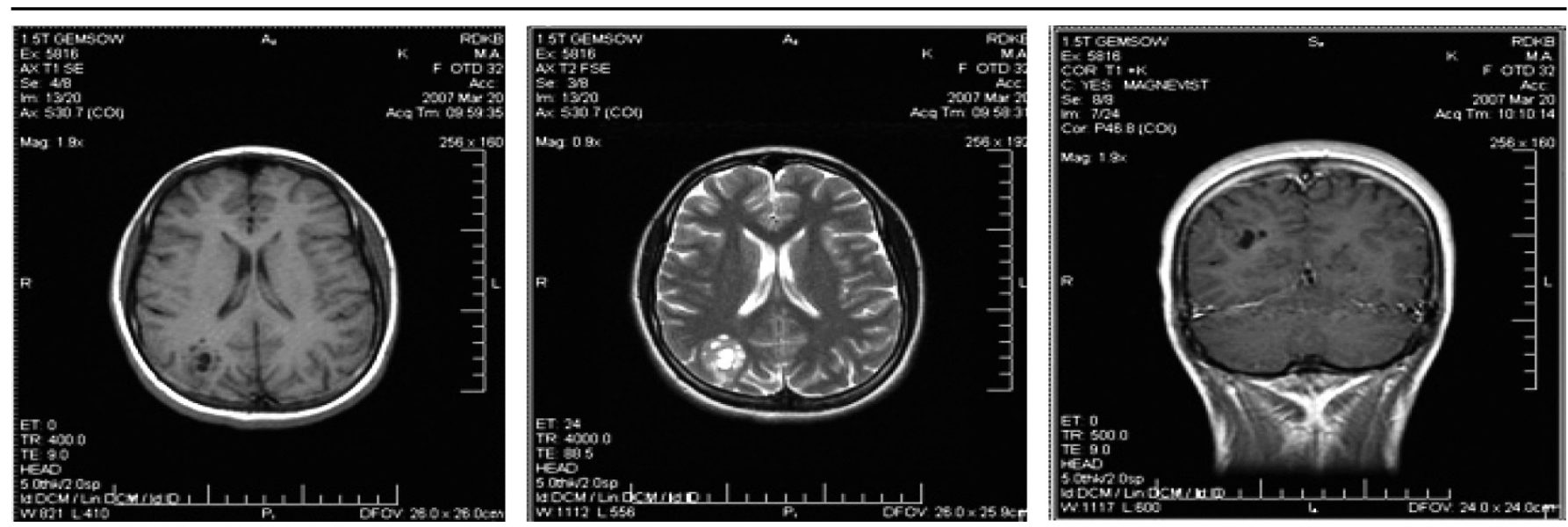

Рис.6. Больная К.М., 14 лет. Ганглиоглиома теменно-затылочной области. На серии МРТ в режиме Т1 - (a), Т2 (б) Т 1 ВИ с контрастированием - (в), визуализируется солидное образование с мелкокистозными включениями (пеноподобная структура), в субкортикальных отделах теменно-затылочного региона справа с вовлечением кортикальной пластинки. перифокального отека и масс-эффекта нет. Рост в динамике не отмечается. При в/в введении МРКС (в) контрастное усиление патологической зоны не выявляется.
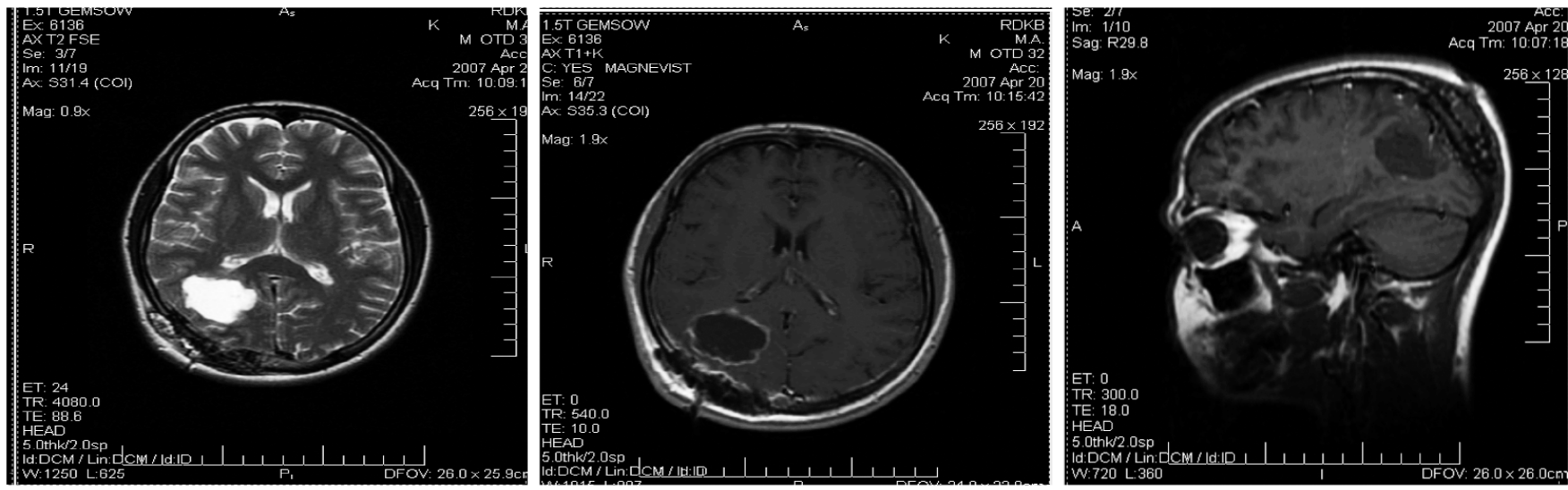

Рис.7. Больная К.М., 14 лет. На серии МР - изображений Т2 - (а) Т 1 ВИ с контрастированием - (б, в), визуализируется зона постоперационных изменений в правой теменно-затылочной области с наличием кистозной полости с реактивным накоплением контрастного агента по границе постоперационных изменений и хирургического доступа.

В постоперационном неврологическом статусе без особенностей. Рекомендовано, продолжать прием АЭП - постоянно, длительно. После операции на фоне приема АЭП не отмечается специфических ощущений вертиго, а также других типов эпилептических приступов. На настоящее время послеоперационный катамнез составляет 7 лет. Отмена АЭП 5 лет назад. Приступов не отмечается исход Engel class I.

Обсуждение. ДНЭО на МРТ обычно имеет изоинтенсивный сигнал на Т1 ВИ и варьирующий по интенсивности от умеренного до гиперинтенсивного сигнал в T2 и FLAIR ВИ (Рис. 1). При ДНЭО, в отличие от целого ряда церебральных опухолей, практически отсутствует масс-эффект и перифокальный отек (Рис. 1, 3, 4). Также в $30 \%$ случаев описано наличие пет- рификатов $[3,6,10,11]$. Зона поражения кортикальной пластинки, зачастую напоминает утолщение коры или бывает представлена в форме узла (узловой компонент опухоли (Рис. $1,4))[12,13]$. Структура опухоли может быть узловой, кистозно-солидной и мультикистозной (множественные микрокисты). Как и в случаях с ГГ, отношение ДНЭО к контрастному усилению опухолевого субстрата неоднозначное [2, 6, 11, 13]. Корниенко В.Н. с соавт. (2006) утверждают, что до $30 \%$ всех диагностированных ДНЭО могут иметь мелкоочаговое контрастное усиление [6]. МР-ангиография может выявить обеднение или отсутствие сосудистого матрикса опухоли [3]. Надо отметить, что некоторые новообразования головного мозга, могут копировать рентгенологические характеристики ДНЭО, в большинстве случаев, это 
ганглиоглиомы, олигодендроглиомы и астроцитомы Gr I, II [3, 9]. При отсутствии роста и наличии кистозно-солидной структуры опухоли, может отмечаться схожая МР-картина с последствиями нейроинфекции, посттравматической или постишемической трансформацией тканей мозга [3, 6, 11].

ДА растет инфильтративно или сочетает инфильтративный рост с экспансивным. При диффузном росте характерно вовлечение в процесс, как белого, так и серого вещества головного мозга, что проявляется стертостью границ между этими структурами и увеличением извилин (Рис. 5) [5, 6]. Считается, что для астроцитомы Gr I, II не характерен массивный перифокальный отек, хотя однозначно отдифференцировать перифокальный отек от тумора не представляется возможным из-за практически одинаковых сигнальных характеристик и отсутствия плотной капсулы (Рис. 5) $[3,6,7]$. Эти опухоли могут поражать несколько долей мозга одновременно, что обусловлено их медленным и зачастую бессимптомным ростом до поздних стадий развития процесса [1, 5, 6, 7]. Как правило, ДА контраст-негативны, но при долгом наблюдении, быстром прогредиентном росте, отмечено присоединение контрастного усиления разных типов, от диффузного мелкоочагового до кистозно-солидного [3, 5, 6, 14]. Возможно развитие и прогрессия масс-эффекта в виде нарастающего смещения окружающих структур и сужения близлежащих субарахноидальных пространств. По данным Корниенко В.Н. и совт. (2006) до 10-12\% всех ДА могут иметь атипичную картину на МРТ - наличие кистозного компонента или иметь интенсивное или очаговое контрастное усиление. При позднем выявлении опухоли, в некоторых случаях, процесс может тотально поражать одно полушарие с вовлечением контралатерального [5, 6]. Надо заметить, что инфильтративный рост может приводить к распространению процесса за пределы видимых изменений на МРТ, что затрудняет определение четких границ опухолевого процесса при резекции [4, 15]. Сигнальные характеристики ДА в типичных случаях, представлены гиперинтенсивным достаточно однородным МР - сигналом на Т2 и FLAIR ВИ и гипо/ или изоинтенсивным сигналом в Т1 ВИ $[3,6,7]$. Высокий потенциал ДА в возникновении эпилепсии отмечен в ряде международных исследований $[1,4,6,15]$.

Визуализационные характеристики ГГ крайне нестабильны, как правило это кистозно-солидная опухоль, которая может достигать размеров от нескольких сантиметров до гигантской мультилобарной $[6,8,16]$. Сигнал от солидного компонента опухоли, обычно гиперинтенсивный в режиме Т2 ВИ и гипоинтенсивный в Т1 ВИ, кистозный компонент, имеет ликворные МР - характеристики и как правило, имеет большие размеры по сравнению с узлом. В некоторых случаях описывается наличие микрокист в структуре опухоли (Рис. 6) [6]. Ряд авторов отмечают, что контрастное усиление может встречаться в 50\% случаев, как и наличие петрификатов [6, 17]. Также как и при ДНЭО, излюбленным местом локализации можно считать височные и теменные доли мозга [3, 6, 8, 17]. Довольно часто ГГ располагается в конвекситальных отделах и вовлекает в процесс кортикальную пластинку (Рис. 6). При этом могут наблюдаться случаи мимикрии этим образованием резидуальных кист кортикальной пластинки $[3,6,8]$. А преобладание кистозного компонента, в глубине которого можно не увидеть мелкого узла и отсутствие роста, нивелирующего динамическую оценку, затрудняют дифференциальный диагноз [3]. Сообщается о ведущей роли ганглиоглиом в формировании эпилепсии у пациентов детского возраста говорится [16]. Учитывая, что ГГ наряду с ДНЭО является одной из наиболее частых причин симптоматической эпилепсии, при наличии неуклонного прогрессирования приступов рекомендуется исключать, прежде всего, присутствие ГГ кортикального расположения [3, 16, 17, 18].

Выводы. Новообразования головного мозга, ассоциированные с симптоматической эпилепсией, встречающиеся в детском возрасте, могут не обладать специфической МР картиной (симптом "+ ткань", перифокальный отек, масс-эффект, прогредиентный рост). Также, они могут быть малых разме- 
ров, располагаться конвекситально, мимикрировать под МР-характеристики друг друга (ДНЭО, ГГ, астроцитомы Gre I, II) или других патологических процессов в головном мозге, а также сочетаться с другими структурными дефектами и аномалиями развития. Учитывая функциональную значимость кортикальной пластинки, прехирургическое использование МРТ ВР в сочетании с ЭЭГ, позволяет более точно очертить зону последующей резекции и предположить сочетание опухолевого процесca c другими патологическими состояниями вещества мозга. При хирургическом лечении фармакорезистентных случаев височной эпилепсии, обусловленных структурными изменениями головного мозга неясной этиологии, рекомендуеся обязательное проведение МРТ

\section{ЛИТЕРАТУРА}

1. Van Breemen M.S., Wilms E.B., Vecht C.J. Epilepsy in patients with brain tumours: epidemiology, mechanisms, and management // Lancet Neurol. - 2007.V.6. P.421-30.

2. Roberto G., Alessandro C., Francesca F., Maria M.M., Maria G.B., Paolo N., Andrea R., Angela P., Miriam T., Armando C., Maria L.G., Pasquale S. Epilepsy associated with supratentorial brain tumors under 3 years of life // Epilepsy Research. - 2009. V.87. P. 184-189.

3. Алиханов А.А., Генералов В.О., Демушкина А.А., Перепелова Е.М., Шимановский Н.Л., Чадаев В.А. Визуализация эпилептогенных поражений головного мозга у детей // Издательский дом Видар. - 2009. c. 199-219.

4. Barcovich A.J, Kuzniecky R.I., Jackson G.D., Guerrini R., Dobyns W.B. A develop-mental and genetic classification for malformations of cortical development // Neurology. - 2005. - V.65. - P.1873-87.

5. Van Veelen ML, Avezaat CJ, Kros JM, van Putten W, Vecht C. Supratentorial low grade astrocytoma: prognostic factors, dedifferentiation, and the issue of early versus late surgery. J Neurol Neurosurg Psychiatry 1998; 64: 581-87.

6. В.Н. Корниенко, И.Н. Пронин Атлас Диагностическая нейрорадиология // Издательство ИП "Андреева T.M. - 2006. - c. 455-599.

7. Urbach H. MRI of long-term epilepsy-associated tumors // Semin Ultrasound CT MRI. - 2008. - V.29 (1). P.40-6.

8. Luyken C., Blumcke I., Fimmers R., Urbach H., Wiestler O.D., Schramm J. Supratentorial gangliogliomas: histopathologic grading and tumor recurrence in 184 patients with a median follow-up of 8 years // Cancer. 2004. - V.101. - P.146-55.

9. Villarejo F., Alvarez-Sastre C., Martinez-Quinones J., Colomar P., Martin-Gamero A.P., Perez-Diaz C. Dysembryoplastic neuroepithelial tumors // Revista de Neurologia. - 1999. - V.29 (9). - P.810-4.
ВР в комплексе прехирургических мероприятий, независимо от результатов, полученных при проведении рутинной МРТ. Особенностями МР - визуализации эпилептогенных опухолей по данным нашего исследовании были: отсутствие масс-эффекта, перифокального отека и существенных изменений размеров и конфигурации выявленных ДНЭО и ГГ. Так называемая "пеноподобная" структура, с наличием множественных микрокист в строме опухоли, лучше всего визуализируется в режимe FLAIR ВИ и может встречаться как при ДНЭО, так и при ГГ. Зона поражения кортикальной пластинки, может быть представлена в форме узла (узловой компонент опухоли), локального утолщения коры или кортикальных (арахноидальных) кист.

10. Fernandez C. Et al. The usefulness of MRI in the diagnosis of disembryoplastic neuroepithelial tumor in children: a study of 14 cases. AJNR, 2003, 24: 829-834.

11. Stanescu Cosson R. Et al. Disembryoplastic neuroepithelial tumors: CT, MR findings and imaging fjlloup: a study of 53 cases. J. Neuroradiol., 2001, 28: 230-240.

12. Barcovich A.J, Congenital malformations of the brain and skull. In: Barcovich A.J, ed. Pediatric neuroimaging 4Th ed. Philadelphia: Lippincott, Williams \& Wilkins, 2005. 291-439.

13. Takahashi A., Hong S.C., Seo D.W., Hong S.B., Lee M., Suh Y.L. Frequent association of cortical dysplasia in dysembryoplastic neuroepithelial tumor treated by epilepsy surgery // Surgical Neurology. - 2005. - V.64(5). - P.41927.

14. Provenzale G.M., Mukundan S., Dewhirst M. The role of blood-brain permeability in brain tumors imaging and therapeutics. Am. J. Roentgenol., 2005, 185: 763-767.

15. Aronica E., Leenstra S., van Veelen C.W., van Rijen P.C., Hulsebos T.J., Tersmette A.C., Yankaya B., Troost, D. Glioneuronal tumors and medically intractable epilepsy: a clinical study with long-term follow-up of seizure outcome after surgery // Epilepsy Res. - 2001. - V.43. - P.179191.

16. Ogiwara H., Nordli D.R., DiPatri A.J., Alden T.D., Bowman R.M., Tomita T. Pediatric epileptogenic gangliogliomas: seizure outcome and surgical results // J. Neurosurg. Pediatr. - 2010. - V.5 (3). - P.271-6.

17. Selch M. Gangliogliomas: experience with 3 patients and review of the literatute. Am. J. Clin. Onc., 1998, 21: 557-564.

18. Morris H.H., Matkovic Z., Estes M.L., Prayson R.A., Comair Y.G., Turnbull J., Najm I., Kotagal P., Wyllie E. Ganglioglioma and intractable epilepsy: clinical and neurophysiologic features and predictors of outcome after surgery // Epilepsia. - 1998. - V.39 (3). - P.307-13. 


\title{
XÜLASə
}

\section{UŞAQLARDA BAŞ BEYNIN EPILEPTOGEN SUPRATENTORİAL ŞIŞLORINIIN CORRAHI ӘMӘLIYYATÖNÜ MR-VIZUALIZASIYYASI}

\author{
Xəlilova V.S. ${ }^{1}$, Xolin A.A..,4, Vasilyev İ.Q. ${ }^{3}$, Rasskazçikov İ.V. ${ }^{3}$, Kislyakov A.N., \\ İsmailova R.R. ${ }^{2}$, Zavadenko N.N. ${ }^{2}$
}

${ }^{1}$ Morkazi uşaq kliniki xəstəxanası, MRT şöbəsi, Moskva, RF;

${ }^{2}$ N.İ.Piraqov adina Rusiya Milli Tadqiqat Tibb Universitetinin pediatrik fakultəsinin nevrologiya, neyrocarrahiyy va tibbi genetika kafedrası, Moskva, RF;

${ }^{3}$ Rusiya uşaq kliniki xastaxanasinin neyrocarrahiyya şöbəsi, Moskva, RF;

${ }^{4}$ Rusiya uşaq kliniki xastəxanasının, 2 sayl psixonevrologiya şöbəsi, Moskva, RF;

${ }^{5}$ Morozov uşaq şəhər kliniki xəstaxanası, patoloji anatomiya şöbəsi, Moskva, RF;

Epilepsiaynın simptomatik fokal formaları çox vaxt baş beyinin supratentorial şişləri səbəbli olur. Baş beyin şişləri diaqnozu ilə 79 uşaq yaşlı pasiyentdən ibarət müayinə qrupunda epilepsiyanın simptomatik forması 56 $(69,3 \%)$ nəfərdə müşahidə olunmuşdur. Daha çox epileptogen olan şişlər dizembrioplastik neyroepitelial şişlər (DNEŞ), diffuz astrositomalar (DA) və qanqlioqliomalar (QQ) olmuşdur. Bizim tərəfimizdən qeyd olunmuş DNEŞ-li halların hamısında və 4 QQ-li pasiyentdə epileptik tutmalar xəstəliyin ilk əlaməti olmuş, 5 DNEŞ-li haldan 4-də şişin yeganə kliniki əlaməti olmuşdur. Neyrovizualizasiya zamanı MR mənzərənin xüsusiyyətləri DNEŞ, DA və QQ üçün T1 rejim görüntülərində izo/hipointensif siqnal və T2, FLAİR rejim görüntülərində intensivliyinə görə orta ifadəli siqnaldan hiperintensiv siqnala qədər olmuşdur ki, bunula yanaş1 DNEŞ, QQ zamanı mass-effekt və perifokal ödem olmamışdır, ancaq FLAİR rejimdə daha aydın köpüyəbənzər (multikistoz) struktur izlənilirdi. Müşahidə müddətində aşkarlanmış DNEŞ və QQ ölçülərində əhəmiyyətli dəyişiklik qeyd olunmamışdır. 1 halda DNEŞ kortikal displaziya ilə birgə müşahidə olunmuşdur. DA zamanı tumoroz toxuma və baş beyinin dəyişilməmiş toxuması ilə perifokal ödemi fərqləndirmək çətindir, şişin inkişafı ləngimişdir. Göstərilən şişlərin kontrast gücləndiriciyə münasibəti birmənalı deyildir. DNEŞ (epileptogenlik $100 \%$ hallarda) ilə yanaşı, DA (91,7\% hallarda) və QQ (80\% hallarda) daha cox epileptogen şişlərdən olmuşdur ki, bunları fokal epilepsiyanın farmakorezistent halları zamanı istisna etmək lazımdır.

Açar sözlər: baş beyin şişləri, simptomatik fokal epilepsiya, neyrovizualizasiya. 


\title{
SUMMARY
}

\section{PRE-SURGERY MR-VISUALIZATION OF THE EPILEPTOGENIC SUPRATENTORIAL BRAIN TUMORS IN CHILDREN}

\author{
Khalilov V.S. ${ }^{\text {, }}$ Kholin A.A. ${ }^{2,4}$, Vasiliev I.G. ${ }^{3}$, Rasskazchikova I.V. ${ }^{3}$, Kislyakov A.N. ${ }^{5}$, \\ Ismailova R.R. ${ }^{2}$, Zavadenko N.N. ${ }^{2}$ \\ ${ }^{1}$ MRT department of FMBA Central Children Clinical Hospital, Moscow; \\ ${ }^{2}$ Department of Child Neurology, Neurosurgery and Medical Genetics, Pirogov Russian National \\ Research Medical University of the Russian Federation Ministry of Heath, Moscow; \\ ${ }^{3}$ Department of Neurosurgery, Russian Children Clinical Hospital, Moscow. \\ ${ }^{4}$ Department of Psychoneurology №2, Russian Children Clinical Hospital of the Russian Federation \\ Ministry of Heath, Moscow; \\ ${ }^{5}$ Pathomorphology Department of Morozov Children Clinical Hospital, Healthcare Department of \\ Moscow
}

Symptomatic focal epilepsies are commonly caused by the supratentorial brain tumors in chtldren. Among the 79 pediatric patients with supratentorial brain tumors 56 patients had symptomatic epilepsy $(69,3 \%)$. The most epileptogenic tumors were dysembryoplastic neuroepithelial tumors (DNET), diffuse astrocytomas (DA) and gangliogliomas (GG). In all the cases of DNET and in 4 patients with GG epileptic seizures were the first manifestation, and in 4 of 5 cases of DNEO they were the only clinical sign of tumor. On the neuroimaging the MR-features of DNET, DA and GG were represented by iso- or hypointensive signal on T1 weighted image (WI) and varying in intensity from moderate to hyperintensive signal in T2 and FLAIR WI, while in cases with DNET and GG practically no mass effect and perifocal edema were seen, and on FLAIR WI the so-called "spume-like" (multicystic) structure was most clearly observed. During the follow up period no significant changes in the dimensions of identified DNET and GG were observed. In one case the combination of DNET with focal cortical dysplasia was noted. In DA it is difficult to distinguish the perifocal edema from tumorous tissue and normal brain tissue, and the growth potential of tumor is slow. The contrast enhancement of these tumors is ambiguous. Along with DNET (which is epileptogenic in $100 \%$ of cases), the most epileptogenic brain tumors are DA (in $91.7 \%$ of cases) and GG (in $80 \%$ of cases) which should be excluded in drug-resistant cases of focal epilepsy.

Keywords: Neurovisualization, brain tumors in children, symptomatic focal epilepsy, epilepsy surgery.

Redaksiyaya daxil olub: 01.06.2015

Çapa tövsiya olunub: 10.06 .2015

Rayçi: prof. Şiroliyeva R.K, 